\section{Final words on malaria's return}

SIR - The evidence offered by Sharma and Mehrotra ${ }^{1}$ does not change our major contentions $^{2}$.

The introduction of high yielding crop varieties has led to the resurgence of malaria in much of southern India's agricultural zone, not because of any inherent feature of the new seeds but because of the technology commonly employed in growing them. Specifically, the intensive use of chemical pesticides leads to increased Anopheles resistance to these chemicals, and to resurgent malaria.

On the question of whether insect susceptibility to chemicals can be reversed, it is possible that mutation may be one of the mechanisms by which individual mosquitoes become resistant to a particular chemical. However, a far more widespread cause of resistance is that of genetic selection within the insect population at large. This phenomenon does not appear to be reversible. In fact, the genetics of resistance suggest that an apparent return to susceptibility may actually be only short-lived. According to Robert Metcalf, for example, "although the gene frequency of a specific resistant allele may decrease upon the removal of insecticide pressure, there persists a changed background of residual inheritance in the genome that causes the strain to regain its resistance as soon as the insecticide is reapplied. . . These factors prevent the successful long term re-use of any insecticide in insect populations with resistant alleles, even though the initial resistance has apparently reverted to full susceptibility." (ref.3). It is thus clear that both farmers and malaria control specialists will have to search for new methods to control their pests.

This brings us to the problem of producing enough food for a growing population. Clearly, developing countries cannot afford to decrease their agricultural yields. By calling for a reduction in pesticide use, we do not mean to imply that food production is less important than malaria control. Rather, integrated pest management offers a potential way out of this impasse and has been successfully implemented with high yielding varieties of cotton, corn, sugar cane and rice in many areas of the developing world, including India ${ }^{4,5}$. With carefully designed integrated pest management systems, countries can continue to increase the production of basic foodstuffs while reducing the selection pressure on Anopheles mosquitoes and other insect vectors of disease.

GEORGANNE CHAPIN ROBERT WASSERSTROM

\section{Columbia University,}

New York, USA

. Sharma, V.P. \& Mchrotra, K.N. Nalure 300, 212 (1982).

. Chapin, G. \& Wasserstrem, R. Nature 293, 181 1 185 (1981)

3. Metealf, R.I.. A. Rev. Ent. 25, 219-256 (1980).

. Brader, L. A. Rev. Eni. 24, 225.254 (1979).

Kirilani, K. A. Rev Ent 24, 279.312(1979)
SIR - To settle the controversy raised by Chapin and Wasserstrom ', we further substantiate that:

Nearly two decades of DDT spraying in human dwellings and cattlesheds did not induce any resistance in exophilic vectors of malaria such as Anopheles philippinensis, which also breeds in paddy fields ${ }^{2}$. Similarly, Anopheles balabacensis has remained susceptible to DDT in India and Bangladesh, although intensive agriculture is being practised in areas of its distribution ${ }^{3}$. Anopheles sundaicus, the vector of malaria in Andaman \& Nicobar island, has remained susceptible, even though liberal use of pesticides has been made to increase agricultural production ${ }^{4}$. The inability of exophilic vectors, in contrast to endophilic vectors, to develop resistance, was attributed to the mosquitoes' reluctance to rest indoors on DDT deposits.

Chemical pesticides used in India to increase agricultural production of rice and cotton did not induce any resistance in the primary target species of these crops ${ }^{5}$ as happened elsewhere ${ }^{6}$.

One of the most difficult obstacles to the successful control of insect pests is their ability to develop resistance, which is preadaptive. Some countermeasures are being investigated but none is at present available for large scale operational use, except the replacement insecticides ${ }^{7}$. Pest control must thus be managed more judiciously until newer technology becomes available for national programmes.

Under the modified plan of operation of the National Malaria Eradication Programme of India, malaria control is based on indoor residual spraying of insecticides, and free drug distribution in even the remotest areas of the country. The programme costs an annual Rs. 1,000 million and there are persistent demands for increased allocations. In India the basic reproduction rate of malaria, in large parts of the country, is very high. With this background, a relaxed view in favour of integrated pest management may be highly detrimental and result in untold human suffering.

\section{Malaria Research Centre (ICMR),}

Delhi, India

V.P. SHARMA

K.N. MEHROT
Indian Agricultural Research Institute, New Delhi, India

1. (hanin, Ci. \& Wasserstrom, R. Nature 293, 181-185 (1981). N. Singh \& Chakrabarti, S.C. J Communicative Dis. 11, $85-88$ (1979).

3. Elias, M. \& Rahman, M. Bangladesh med. Res. Council Bull. 7, 1-6(1981)

4. Kalra, N.J. J. Communicative Dis. 13(1), 45-52 (1981).

5. Senapati, B. \& Salpathy, J.M. J. ent. Res. 4. 139-147 (1980).

6. Metcalf, R.1. J. Agric Fd Chem. 21, 511.520 (1973)

7. Georghiou, (i.P. Residue Rev. 76, 131-145 (1980).

This correspondence is now closed -Editor, Nature.

\section{Rescue mission for British mussel}

SIR - I was most interested by Dr R. Robert's review' ${ }^{1}$ of Isom and Hudson's recent report about a culture technique for the glochidia of freshwater mussels ${ }^{2}$. The British species, Margaritifera margaritifera (L.) is indeed endangered and in need of urgent conservation measures, however, we unfortunately feel that Isom and Hudson's technique will not be of great relevance in Britain, at least at present.

It is already technically easy, although rather laborious, to infect stock fish with glochidin and then retrieve viable mussels from them. The real difficulty which must be overcome before $M$. margaritifera can be restocked successfully, is that no-one has succeeded in rearing the young mussels after their release from their host fish. They are tiny $(0.5 \mathrm{~mm}$ diameter $)$ and have proved impossible to rear for more than a few months. All attempts at introducing such young mussels into even very favourable natural sites have so far failed and until this problem can be overcome glochidial culture will not help.

Our view ${ }^{3}$ is that urgent conservation measures must be applied to restrict overfishing. In Scotland almost all populations have been fished for pearls, to the point where their survival is in doubt, and unless the mussel is to be reduced to a few, isolated populations in protected areas, action is needed. What seems most unlikely is that the political and economic climate will allow measures which will work and which can be effectively policed.

MARK R. YOUNG: JENNIFER C. WILLIAMS

Department of Zoology

University of Aberdeen, $U K$

1. Roberts, R.J. Nature 302, 13 (1983).

. Isom, B.(i. \& Hudson, R.(i. Nautilus 96, 147 (1982).

3. Young, M.R. \& W'illians, I.C. Biol. Conservation 25. $35-52(1983)$

\section{Crno!p pltogh}

SIR - I have long regarded your journal as a valuable source of news about the world of science. However, if I judge the accuracy of the general content by a lew items of which I have direct personal knowledge, I must begin to question its reliability. I refer to three examples in the issue of 27 January: One of the Cireat l.akes has become Eyric inslcad of Eric (p.285); the director of Fermilab has been changed from L.con I.cederman to Icon I.ctlerman (p.273); and Big Brother, ereated by (ieorge Crwell, has been ascribed to Aldous Huxlcy (p.271). If you fail in these small things, how can we trust you in the large?

Citcrial 1. Trice, (Editor, Physical Review Letters) New York, USA 